\title{
Synthesis and Polymerization of Methylvinylthiosilanes
}

\author{
Shun-ichi Nozakura, Yasushi Yamamoto, and Shunsuke Murahashi \\ Department of Polymer Science, Faculty of Science, \\ Osaka University, Toyonaka, Osaka, 560 Japan.
}

(Received January 11, 1973)

\begin{abstract}
Methylvinylthiosilanes, $\left(\mathrm{CH}_{3}\right)_{4-n} \mathrm{Si}\left(\mathrm{SCH}=\mathrm{CH}_{2}\right)_{n} \quad(n=1-3)$, were first synthesized by the reaction of the corresponding methylchlorosilanes and vinylthiomagnesium bromide.

All these vinylthiosilanes were found polymerizable by a radical initiator. The radical polymerization of di- and trivinylthiosilanes seemed to involve cyclopolymerization. The rate of radical homopolymerization was found to be almost independent of the number of the vinylthio group.

There was no significant difference between trimethylvinylthiosilane and vinylthiocarbon compounds in radical copolymerizability. The cationic polymerization did not give high-molecular-weight products.

A radical homopolymer of trimethylvinylthiosilane was converted into poly(vinylmercaptan) by methanolysis.
\end{abstract}

KEY WORDS Methylvinylthiosilane/Vinylthiomagnesium Bromide/

Radical Polymerization / Cationic Polymerization / Radical Copolymerization / Styrene / Poly(vinyl mercaptan) /

In previous papers, ${ }^{1}$ it has been reported that vinyloxysilanes are polymerizable by cationic mechanisms and that the polymers are convertible into poly(vinyl alcohol) by hydrolysis of the C-O-Si linkage.

Similarly, vinylthiosilanes can be regarded as a new monomeric precursor to poly(vinyl mercaptan) due to its characteristic $\mathrm{C}-\mathrm{S}-\mathrm{Si}$ linkage, but they have not yet been synthesized.<smiles>C=C(S)CCC(CCC(C)S)SCC</smiles>

The object of the present work is to attempt to synthesize a series of fundamental derivatives of vinylthiosilanes and to study the polymerizability and other properties.

Polymercaptans are being investigated as possible radiation prophylactics, as model systems for enzymatic processes, and as exchange resins for the removal of heavy-metal ions. A limited number of synthetic sulfhydryl polymers have previously been prepared by addition polymerization, ${ }^{2}$ as well as by condensation polymerization. $^{3}$ Poly(vinyl mercaptan) has been prepared by the hydrolysis of $\operatorname{poly}(S \text {-vinyl thiolacetate })^{4}$ and $\operatorname{poly}(S \text {-vinyl-O- } t \text {-butyl thiolcarbonate })^{5}$ which were polymerized by radical mechanisms.

\section{Preparation of Monomer}

Many unsuccessful attempts were made by the present authors to synthesize an unknown compound, $\beta$-chloroethylthiotrimethylsilane, from which vinylthiotrimethylsilane might be prepared by dehydrochlorination.

Methylvinylthiosilanes were synthesized by the reaction of vinylthiomagnesium bromide and chloromethylsilanes according to the following scheme.

$$
\begin{aligned}
\mathrm{CH}_{2}= & \mathrm{CHBr} \underset{\mathrm{THF}}{\stackrel{\mathrm{Mg}}{\longrightarrow}} \mathrm{CH}_{2}=\mathrm{CH}-\mathrm{MgBr} \\
& \stackrel{\mathrm{S}}{\longrightarrow} \mathrm{CH}_{2}=\mathrm{CH}-\mathrm{SMgBr} \\
\left(\mathrm{CH}_{3}\right)_{4-n} \mathrm{SiCl}_{n}+n \mathrm{CH}_{2}=\mathrm{CH}-\mathrm{SMgBr} & \longrightarrow\left(\mathrm{CH}_{3}\right)_{4-n} \mathrm{Si}\left(\mathrm{SCH}=\mathrm{CH}_{2}\right)_{n}+n \mathrm{MgBrCl}
\end{aligned}
$$

But from these compounds tetravinylthiosilane could not be obtained as a pure product. The results of the syntheses of methylvinylthiosilanes are summarized in Table I.

Figure 1 shows the IR spectra of methylvinylthiosilanes. Upon increasing the number of vinylthio groups, no variations were found in the positions of the absorption bands at $1587 \mathrm{~cm}^{-1}$ $\left(\nu_{\mathrm{C}=\mathrm{C}}\right)$ and at $1248 \mathrm{~cm}^{-1}\left(\delta_{\mathrm{Si}-\mathrm{CH}_{3}}\right)$, but the 
Table I. Synthesis of methylvinylthiosilane; $\left(\mathrm{CH}_{3}\right)_{4-n} \mathrm{Si}\left(\mathrm{SCH}=\mathrm{CH}_{2}\right)_{n}(n=1-3)$

\begin{tabular}{lccc}
\hline$n$ & 1 & 2 & 3 \\
\hline Yield, \% & 36 & 26 & 11 \\
Bp, & $125-126 / 760$ & $75.5-76 / 10$ & $95.5 / 2$ \\
${ }^{\circ} \mathrm{C} / \mathrm{mmHg}$ & 1.473 & 1.540 & 1.581 \\
$n_{\mathrm{D}}^{25}$ & 0.850 & 0.999 & 1.108 \\
$d_{4}^{25}$ & & & \\
Anal. obsd(calcd) & $45.51(45.39)$ & $40.28(40.87)$ & $38.44(38.16)$ \\
$\mathrm{C}, \%$ & $9.16(9.14)$ & $6.88(6.86)$ & $5.57(5.49)$ \\
$\mathrm{H}, \%$ & $23.91(24.24)$ & $36.68(36.37)$ & $42.50(43.66)$ \\
$\mathrm{S}, \%$ & & &
\end{tabular}

absorption assigned to $\mathrm{Si}-\mathrm{S}$ in the region of 450 to $550 \mathrm{~cm}^{-1}$ shifted to higher frequencies and became broader. NMR data of methylvinylthiosilanes are summarized in Table II. Increasing the number of vinylthio groups caused a downfield shift for both methyl and vinyl protons and a slight decrease in all coupling constants. Proton chemical shifts and coupling constants of organosilicon compounds have been interpreted as indicating the presence of $d \pi-p \pi$ delocalization when the atoms or groups bonded to the silicon possess suitable lone-pair or $\pi$-electrons.

Following Vogel's deduction ${ }^{6}$ it may be deduced that the $d \pi-p \pi$ delocalization is not greatly present in vinylthiosilanes by the following reasoning: the variation of chemical shifts of the methyl protons with a variation of the number of vinyl groups is similar to those of carbon analogues $^{7}$ where the $d \pi-p \pi$ delocalization is absent, and is not similar to those of vinyloxysilanes ${ }^{7}$ where the $d \pi-p \pi$ delocalization is present. In the cases of vinylthiosilanes and vinyloxycarbon derivatives the chemical shifts of methyl protons showed an intensive downfield shift with increasing number of vinyl groups, while vinyloxysilicon compounds showed only small shifts.

\section{Polymerization}

Radical Polymerization. Vinyl ethers are not polymerized by radical initiators, but both divinyl acetals and divinyl ketals are polymerizable. ${ }^{7,8}$ Vinyloxysilanes $\left(\mathrm{CH}_{3}\right)_{4-n} \mathrm{Si}\left(\mathrm{OCH}=\mathrm{CH}_{2}\right)_{n}(n=1-$ 4) show a similar result and the initial rate of polymerization increases markedly upon increasing the number of the vinyloxy groups. ${ }^{7}$

Results of the radical homopolymerization of methylvinylthiosilanes are shown in Table III.

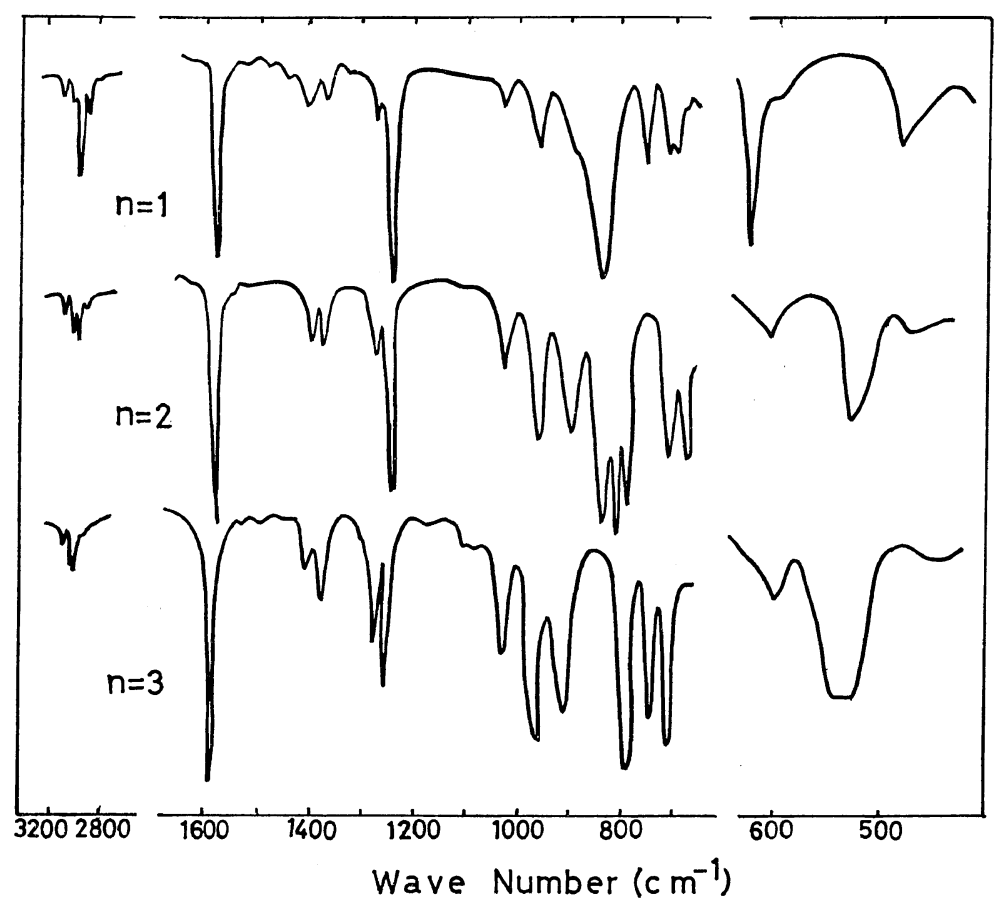

Figure 1. IR spectra of $\left(\mathrm{CH}_{3}\right)_{4-n} \mathrm{Si}\left(\mathrm{SCH}=\mathrm{CH}_{2}\right)_{n}(n=1-3)$. 
Table II. NMR data of methylvinylthiosilanes ${ }^{\mathrm{a}}$ :

\begin{tabular}{|c|c|c|c|}
\hline$n$ & 1 & 2 & 3 \\
\hline $\mathbf{J}_{\mathrm{bc}}$ & 0.9 & 0.8 & $0.6 \mathrm{~Hz}$ \\
\hline $\mathbf{J}_{\mathrm{ab}}$ & 9.2 & 8.4 & 7.7 \\
\hline $\mathbf{J}_{\mathrm{ac}}$ & 17.2 & 17.2 & 16.8 \\
\hline$\delta_{\mathrm{a}}$ & 6.27 & 6.43 & $6.45 \mathrm{ppm}$ \\
\hline$\delta_{\mathrm{b}}$ & 5.40 & 5.58 & 5.63 \\
\hline$\delta_{\mathrm{c}}$ & 5.43 & 5.62 & 5.66 \\
\hline$\delta_{\mathrm{CH}_{3}}$ & 0.33 & 0.58 & 0.83 \\
\hline
\end{tabular}

a $\delta$-Values were obtained in $\mathrm{CCl}_{4}$ solution $(10 \%)$ using TMS as internal standard.

It was found that all methylvinylthiosilanes could easily be homopolymerized by $\alpha, \alpha^{\prime}$-azobisisobutyronitrile (AIBN) regardless of the number of vinylthio groups. This result contrasts with that for methylvinyloxysilanes. On the assumption that the absorption coefficients of $\delta_{\mathrm{Si}-\mathrm{CH}_{3}}$ and $\nu_{\mathrm{C}=\mathrm{C}}$ are the same for both monomers and polymers, the content of the pendant vinyl group was found to be about $20 \%$ for poly(dimethyldivinylthiosilane) and about $30 \%$ for poly(methyltrivinylthiosilane). Poly(trimethylvinylthiosilane) was soluble $([\eta]=0.2 \mathrm{~d} l / \mathrm{g})$ in benzene at $60^{\circ} \mathrm{C}$.
Table III. Radical polymerization of $\left(\mathrm{CH}_{3}\right)_{4-n} \mathrm{Si}\left(\mathrm{SCH}=\mathrm{CH}_{2}\right)_{n}$ in benzene at $60^{\circ} \mathrm{Ca}^{\mathrm{a}}$

\begin{tabular}{cccc}
\hline$n$ & Time, hr & $\begin{array}{c}\text { Conversion, } \\
\%\end{array}$ & $\begin{array}{c}\text { Pendant vinyl, } \\
\text { mol } \%\end{array}$ \\
\hline 1 & 3 & 12.2 & - \\
2 & 2 & 9.5 & 20 \\
3 & 2 & 8.0 & 30 \\
\hline${ }^{\mathrm{a}}[\mathrm{M}], 2.0 \mathrm{~mol} / l$ as & vinyl concentration; [AIBN], \\
$1.1 \times 10^{-2} \mathrm{~mol} / l$. &
\end{tabular}

Poly(dimethyldivinylthiosilane) was soluble when isolated at low conversions, but became insoluble at high conversions. Poly(methyltrivinylthiosilane) was insoluble. IR spectra of the polymers are shown in Figure 2.

These results indicate that the cyclopolymerization has taken place to some extent. If the cyclopolymerization and the cross-linking polymerization did not occur, the content of the pendant vinyl group would have been $50 \%$ for poly(divinylthiosilane) and $66.7 \%$ for poly(trivinylthiosilane).

Radical Copolymerization with Styrene. It has been demonstrated that the Alfrey-Price $Q$-values of vinylthiocarbon compounds are relatively high and that the $3 d$-orbital resonance of the sulfur atom is important in the transition state of the copolymerizations. ${ }^{9,10}$

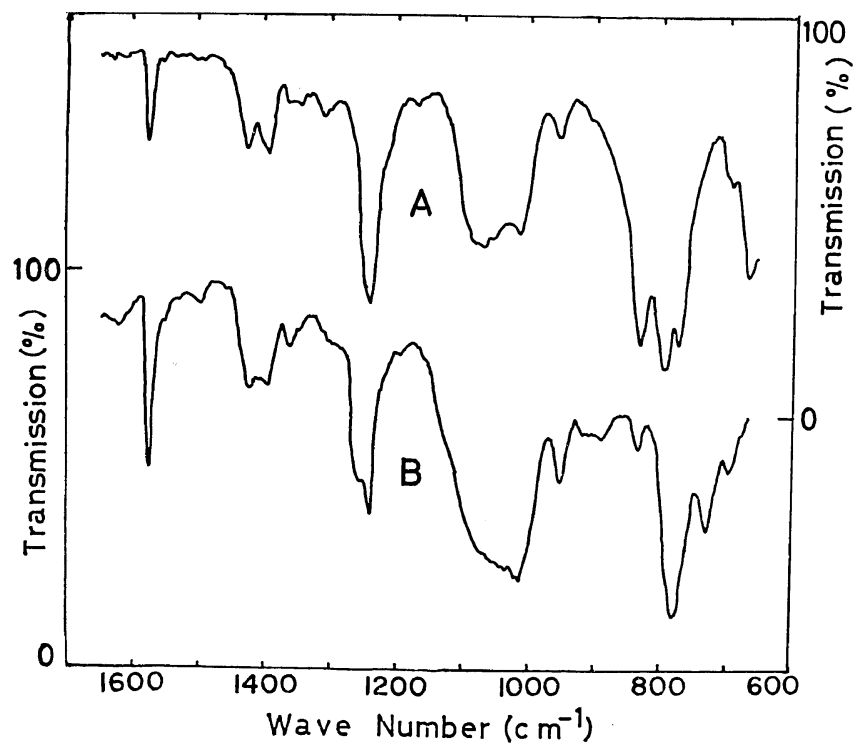

Figure 2. IR spectra of poly(dimethyldivinylthiosilane) and poly(methyltrivinylthiosilane). 
Table IV. Bulk copolymerization of styrene $\left(M_{1}\right)$ and trimethylvinylthiosilane $\left(\mathbf{M}_{2}\right)$ initiated by AIBNa

\begin{tabular}{ccccc}
\hline $\begin{array}{c}\left.\mathrm{M}_{2}\right] \text { in } \\
\text { comono- } \\
\begin{array}{c}\text { mer, } \\
\text { mol\% }\end{array}\end{array}$ & $\begin{array}{c}\text { Time, } \\
\text { hr }\end{array}$ & $\begin{array}{c}\text { Conver- } \\
\text { sion, } \\
\%\end{array}$ & \multicolumn{2}{c}{ Copolymer } \\
\hline 22.3 & 3.5 & 4.6 & 1.15 & $\begin{array}{c}\text { S, } \% \\
{\left[\mathrm{~m}_{2}\right],} \\
\mathrm{mol} \%\end{array}$ \\
39.5 & 7.0 & 6.7 & 2.20 & 7.3 \\
59.8 & 10.0 & 6.5 & 4.56 & 15.4 \\
65.0 & 15.5 & 9.2 & 5.58 & 19.1 \\
74.2 & 13.0 & 7.1 & 7.79 & 27.2 \\
\hline
\end{tabular}

a $[\mathrm{AIBN}], 5 \times 10^{-3} \mathrm{~mol} / l$.

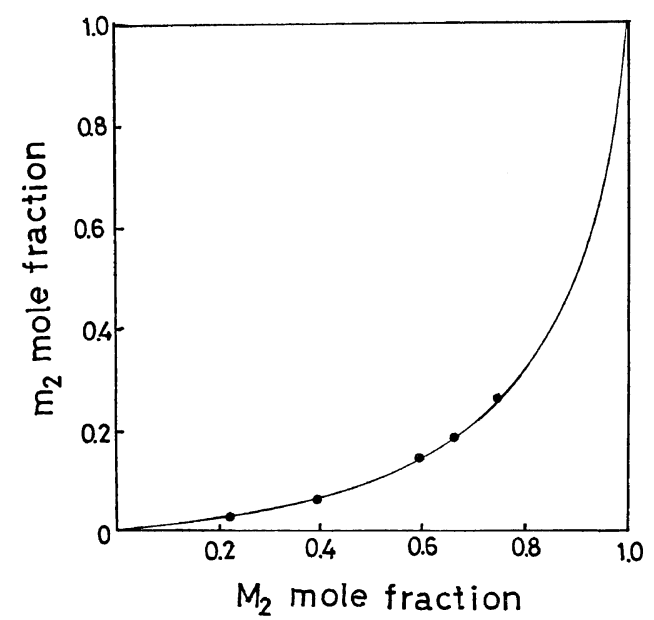

Figure 3. Copolymer composition curve for the radical copolymerization of styrene $\left(M_{1}\right)$ - trimethylvinylthiosilane $\left(\mathrm{M}_{2}\right)$ at $60^{\circ} \mathrm{C}$. (The curve is calculated according to $\left.r_{1}=7.49, r_{2}=0.07\right) . \quad M_{2}$ and $\mathrm{m}_{2}$ represent the mole fraction of trimethyvinylthiosilane in monomer feed and in copolymers.
Table V. Copolymerization parameters

\begin{tabular}{lcl}
\hline \multicolumn{1}{c}{ Monomer } & $Q$ & \multicolumn{1}{c}{$e$} \\
\hline$\left(\mathrm{CH}_{3}\right)_{3} \mathrm{SiSCH}=\mathrm{CH}_{2}$ & 0.25 & -1.60 \\
$S$-Vinyl thiolacetate & 0.31 & $-1.46^{12}$ \\
Methyl vinyl sulfide & 0.32 & $-1.45^{13}$ \\
Phenyl vinyl sulfide & 0.34 & $-1.40^{14}$ \\
$t$-Butyl vinyl sulfide & 0.26 & $-1.1^{10}$ \\
\hline
\end{tabular}

The UV spectra of alkylthiosilane compounds provide evidence for the interaction between the $3 d$-orbitals of the sulfur and silicon atoms. ${ }^{11}$ In order to consider the effect of this interaction on the radical polymerizability of methylvinylthiosilanes, the radical copolymerization of trimethylvinylthiosilane $\left(M_{2}\right)$ with styrene $\left(M_{1}\right)$ was investigated. The results of the copolymerizations are shown in Table IV. The monomer-copolymer composition curve is given in Figure 3. The composition of the copolymer was calculated from its sulfur analysis. The monomer reactivity ratios were obtained by the Fineman-Ross method as follows

$$
r_{1}=7.49 \pm 0.38, \quad r_{2}=0.07 \pm 0.08
$$

Table V summarizes the known $Q$ - and $e$-values of vinylthiocarbon compounds and trimethylvinylthiosilane. The $Q$ - and $e$-values of trimethylvinylthiosilane are nearly equal to those of vinylthiocarbon compounds. As the result, it can be deduced that there is no effect from the interaction between the $3 d$-orbitals of the sulfur and silicon atoms on the reactivity of trimethylvinylthiosilane.

Cationic polymerization. The e-value of tri-

Table VI. Cationic polymerization of $\left(\mathrm{CH}_{3}\right)_{4-n} \mathrm{Si}\left(\mathrm{SCH}=\mathrm{CH}_{2}\right)_{n}(n=1,2)$

\begin{tabular}{|c|c|c|c|c|c|c|c|}
\hline Monomer & Catalyst & Solvent & $\begin{array}{l}{[\mathrm{M}],} \\
\mathrm{mol} / l\end{array}$ & $\begin{array}{c}{[\mathrm{C}],} \\
\mathrm{mol} / \mathrm{l}\end{array}$ & $\underset{{ }^{\circ} \mathrm{C}}{\text { Temp }}$ & $\underset{\mathrm{hr}}{\mathrm{Time}}$ & $\underset{\%}{\text { Conversion, }}$ \\
\hline$n=1$ & $\mathrm{BF}_{3} \mathrm{Et}_{2} \mathrm{O}$ & Toluene & $4 \times 10^{-1}$ & $1 \times 10^{-2}$ & -78 & 6 & $10^{a}$ \\
\hline 1 & $\mathrm{BF}_{3} \mathrm{Et}_{2} \mathrm{O}$ & Toluene & 5 & $5 \times 10^{-2}$ & 60 & 288 & 10 \\
\hline 1 & $\mathrm{BF}_{3} \mathrm{Et}_{2} \mathrm{O}$ & - & bulk & $8 \times 10^{-2}$ & 60 & 3 & 3 \\
\hline 1 & $\mathrm{I}_{2}$ & Benzene & $3.5 \times 10^{-1}$ & $1.4 \times 10^{-2}$ & 50 & 26 & $20^{a}$ \\
\hline 1 & $\mathrm{SnCl}_{4}$ & - & bulk & $4 \times 10^{-2}$ & 60 & 3 & 4.5 \\
\hline 1 & $\mathrm{SnCl}_{4}$ & $\mathrm{EtNO}_{2}$ & 5 & $5 \times 10^{-2}$ & -78 & 72 & 5.5 \\
\hline 1 & - & $\mathrm{SO}_{2}$ & $3 \times 10^{-1}$ & - & -20 & 15 & 50 \\
\hline 2 & $\mathrm{BF}_{3} \mathrm{Et}_{2} \mathrm{O}$ & Toluene & 5 & $5 \times 10^{-2}$ & 0 & 24 & 5.5 \\
\hline
\end{tabular}

a Polymerization was terminated with $\mathrm{NEt}_{3}$. 
Synthesis and Polymerization of Methylvinylthiosilanes
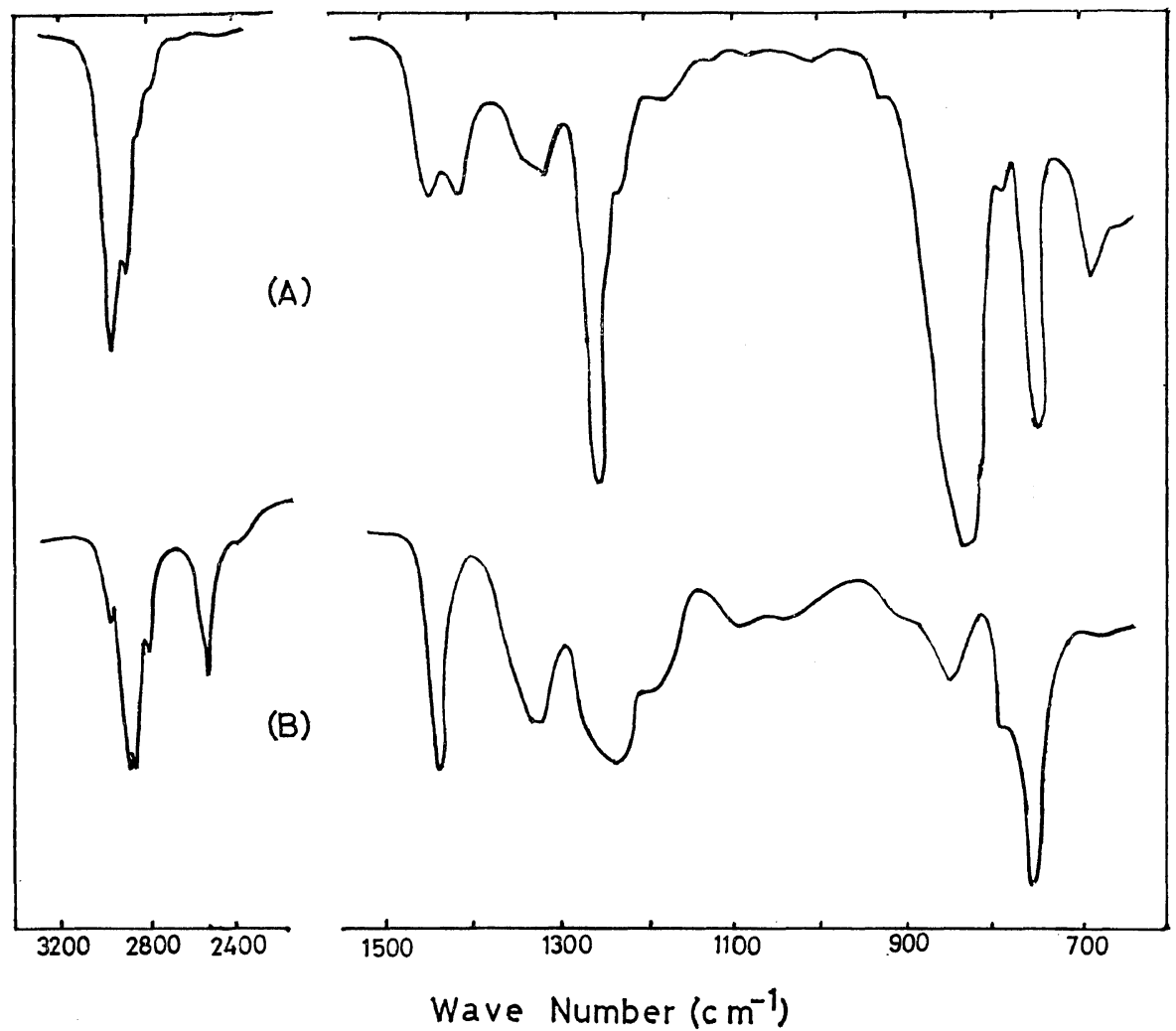

Figure 4. IR spectra of poly(trimethylvinylthiosilane), (A) and poly(vinyl mercaptan), (B).

methylvinylthiosilane indicates the possibility of cationic polymerization, which might give a new route to stereoregular poly(vinyl mercaptan). Methylvinylthiosilanes were polymerized by typical cationic initiators. The results are shown in Table VI. All products were viscous liquids or semisolids. Their infrared spectra showed the presence of vinyl groups. Therefore they seemed to be oligomers or polymers of low molecular weight.

It has been reported that benzyl vinyl sulfide and liquid sulfur dioxide give a 1:1 copolymer in the presence of air. ${ }^{15}$ But the IR spectrum of the product of trimethylvinylthiosilane and liquid sulfur dioxide did not show the presence of $\mathrm{SO}_{2}$ groups. It seemed not to be a copolymer. The product immediately solidified in air and became insoluble, and then the IR spectrum showed the presence of the trimethylsilyl group and the disappearance of the remaining vinyl group.

\section{Conversion to Poly(vinyl mercaptan)}

Poly(vinyl mercaptan) was obtained by methanolysis of the radical homopolymer of trimethylvinylthiosilane in the presence of $\mathrm{HCl}$. The polymer was soluble in $\mathrm{CHCl}_{3}$ but became gradually insoluble when allowed to stand in air. The phenomena may be due to the oxidation of thiols to disulfides by molecular oxygen. The IR spectra of poly(trimethylvinylthiosilane) and poly(vinyl mercaptan) are shown in Figure 4. In the spectrum of poly(vinyl mercaptan), there is a strong absorption at $2520 \mathrm{~cm}^{-1}$ which is assignable to the $\mathrm{SH}$ group. The polymer appeared to be rather impure, as following analytical data indicates.

Anal. Calcd for $\left(\mathrm{CH}_{2} \mathrm{CHSH}\right)_{n}$ :

$$
\text { C, 39.96; H. 6.71; S, 53.34. }
$$

Found: C, 49.64; H, 6.85; S, 42.99 .

\section{EXPERIMENTAL}

All reactions and manipulations involving air- 
sensitive compounds were carried out in an atmosphere of dry nitrogen.

\section{Preparation of Monomer}

Synthesis of $\mathrm{CH}_{2}=\mathrm{CHSMgBr} .^{16}$ Vinylmagnesium bromide was prepared in $85-\%$ yield from $196 \mathrm{~g}(1.84 \mathrm{~mol})$ of vinyl bromide and $36.5 \mathrm{~g}$ $(1.5 \mathrm{~mol})$ of magnesium in THF. Then $38.4 \mathrm{~g}$ (1.2 atom) of powdered sulfur was added with stirring and ice-cooling in small portions over a period of half an hour. The mixture was then heated to boiling and allowed to cool, depositing a green precipitate of vinylthiomagnesium bromide. The precipitate gave a negative Gilman's test. The double titration of the reaction mixture with $\mathrm{HCl}$ and $\mathrm{NaOH}$ showed that vinylthiomagnesium bromide was prepared in about $90-\%$ yield.

Synthesis of $\left(\mathrm{CH}_{3}\right) \mathrm{SiSCH}=\mathrm{CH}_{2}$. To the reaction mixture of vinylthiomagnesium bromide prepared above, $119.5 \mathrm{~g}(1.1 \mathrm{~mol})$ of trimethylchlorosilane was added dropwise with ice-cooling. An exothermic reaction occurred and the green crystals turned gray. After the addition, the reaction mixture was heated under reflux for half an hour. From this reaction mixture, volatile parts were collected in a Dry Ice-methanol trap by evaporation at $110^{\circ} \mathrm{C}$ under reduced pressure. After a simple distillation of the condensate, the distillate was thrice subjected to rectification through a fractionating column packed with stainless-steel helices for $60 \mathrm{~cm}$ (bp $125-126^{\circ} \mathrm{C}$, yield $36 \%$ ). Its purity was at least $99.9 \%$ by gas chromatography (Apiezon grease/celite, $1.5 \mathrm{~m}$ ). As by-products, di(trimethylsilyl)acetylene (bp $\left.133-5^{\circ} \mathrm{C}\right)^{17}$ and hexamethyldisilthiane (bp 162.5$\left.163.5^{\circ} \mathrm{C}\right)^{18}$ were produced and removed from the product by careful rectification.

Synthesis of $\left(\mathrm{CH}_{3}\right)_{2} \mathrm{Si}\left(\mathrm{SCH}=\mathrm{CH}_{2}\right)_{2}$. According to the procedure described above, a THF solution of vinylthiomagnesium bromide which was prepared from $20 \mathrm{~g}(0.8 \mathrm{~mol})$ of magnesium, $107 \mathrm{~g}$ $(1.0 \mathrm{~mol})$ of vinyl bromide, and $22.4 \mathrm{~g}(0.7 \mathrm{atom})$ of sulfur was reacted with $45 \mathrm{~g}(0.35 \mathrm{~mol})$ of dimethyldichlorosilane. All volatile material was removed from the reaction flask under reduced pressure by heating up to $130^{\circ} \mathrm{C}$ and then condensing at $-78^{\circ} \mathrm{C}$. After a simple distillation under reduced pressure, the distillate was subjected to rectification through the fractionating column (bp $75.5-76^{\circ} \mathrm{C}(10 \mathrm{mmHg})$, yield $\left.26 \%\right)$.
The purity of the product was more than $99 \%$ by gas chromatography.

Synthesis of $\mathrm{CH}_{3} \mathrm{Si}\left(\mathrm{SCH}=\mathrm{CH}_{2}\right)_{3}$. To a THF solution of vinylthiomagnesium bromide, prepared from $22.0 \mathrm{~g}(0.9 \mathrm{~mol})$ of magnesium, $113 \mathrm{~g}$ ( $1.06 \mathrm{~mol})$ of vinyl bromide, and $25.6 \mathrm{~g}(0.8 \mathrm{atom})$ of sulfur, was added $40 \mathrm{~g}(0.26 \mathrm{~mol})$ of methyltrichlorosilane. After the addition the mixture was refluxed for $7 \mathrm{hr}$. All volatile material was removed under reduced pressure by heating up to $180^{\circ} \mathrm{C}$ and then condensing at $-78^{\circ} \mathrm{C}$. The condensate was fractionated undr reduced pressure through a Vigreux column (bp $95.5^{\circ} \mathrm{C}(2 \mathrm{mmHg})$, yield $11 \%$ ). Its purity was about $99 \%$ by gas chromatography.

Reaction between Vinylthiomagnesium Bromide and Tetrachlorosilane. In an attempt to synthesize tetravinylthiosilane, $42.6 \mathrm{~g}(0.25 \mathrm{~mol})$ of tetrachlorosilane was added into a THF solution of vinylthiomagnesium bromide, prepared from $29 \mathrm{~g}$ $(1.2 \mathrm{~mol})$ of magnesium, $150 \mathrm{~g}$ (1.41 mol) of vinyl bromide, and $32 \mathrm{~g}$ ( 1 atom) of sulfur. After the addition the reaction mixture was refluxed for $5 \mathrm{hr}$. From this reaction mixture, a volatile material was removed under reduced pressure of $2-3 \mathrm{mmHg}$ by heating up to $170^{\circ} \mathrm{C}$ and then condensing at $-78^{\circ} \mathrm{C}$. After the evaporation of THF in vacuo, however, the residue was not obtained in isolable quantity. The IR spectrum of the residue showed an absorption band at $1585 \mathrm{~cm}^{-1}$ assignable to a vinylthio group.

\section{Material}

Methylvinylthiosilanes and styrene were distilled just before use. AIBN was recrystalized from ethanol. $\mathrm{BF}_{3} \mathrm{Et}_{2} \mathrm{O}$ and $\mathrm{SnCl}_{4}$ were purified by distillation. Benzene and toluene were purified by ordinary methods. Liquid $\mathrm{SO}_{2}$ was obtained from that in a commercial cylinder by liquefaction of the gas, which was previously bubbled through concd $\mathrm{H}_{2} \mathrm{SO}_{4}$.

\section{Radical Polymerization}

The polymerization was carried out in a sealed tube at $60^{\circ} \mathrm{C}$. Required amounts of monomers, benzene, and AIBN in a benzene solution were charged into a glass ampoule tube by a syringe, and the content of the ampoule was then degassed under vacuum by the conventional freezing and thawing technique and sealed off under vacuum. Polymerizations were terminated by cooling fol- 
lowed by the addition of $t$-butylcatechol. The solvent and unpolymerized monomer were removed under high vacuum. Conversion was calculated from the amount of the residual polymer.

Bulk copolymerizations of trimethylvinylthiosilane and styrene were carried out to conversions of lower than $10 \%$ in sealed tubes at $60^{\circ} \mathrm{C}$. Copolymerizations were terminated by the addition of hydroquinone and then unpolymerized monomers were removed under reduced pressure. The resulting copolymers were purified by reprecipitating the benzene solution with an excess of $n$ hexane.

In cationic polymerizations, monomer and solvent were cooled to a desired temperature under nitrogen and a cationic initiator was added. In some cases, polymerizations were terminated by the addition of triethylamine. The products were obtained as a residue by removing solvent and unpolymerized monomer under reduced pressure.

Conversion to Poly(vinyl mercaptan)

A polymer of trimethylvinylthiosilane was dissolved in a 1:1 solution of benzene and methanol, which was previously degassed, and allowed to stand overnight at room temperature after the addition of a few drops of concd $\mathrm{HCl}$. Volatile materials were evaporated under reduced pressure and the residue was dissolved in chloroform. Insoluble parts were removed with a glass filter and poly(vinyl mercaptan) was obtained from the filtrate by evaporation of chloroform.

\section{REFERENCES}

1. S. Murahashi, S. Nozakura, and M. Sumi, $J$. Polym. Sci., Part B, 3, 245 (1965).

2. C. G. Overberger and H. Ashkenasy, J. Org. Chem., 25, 1648 (1960).

3. C. G. Overberger and H. Ashkenasy, J. Amer. Chem. Soc., 82, 4357 (1960).

4. M. M. Brubaker, U.S. Patent 2378535 (1945).

5. C. G. Overberger, J. Amer. Chem. Soc., 86, 3402 (1964).

6. C. W. N. Cumper, A. Melnikoff, E. F. Mooney, and A. I. Vogel, J. Chem. Soc., Sect B, 874 (1966).

7. M. Furue, Dr. Sci. Thesis, Osaka University, 1969.

8. S. G. Matsoyan, J. Polym. Sci., 52, 189 (1961); S. G. Matsoyan and A. A. Soakyan, Polymer Sci. USSR, 3, 921 (1961).

9. C. G. Overberger, Makromol. Chem., 64, 126 (1963).

10. T. Otsu and H. Inoue, J. Makromol. Sci.Chem., A4, 35 (1970).

11. W. N. Cumper, A. Melnikoff, and A. I. Vogel., J. Chem. Soc., Sect A, 242 (1966).

12. C. G. Overberger, H. Biletch, and R.G. Nickerson, J. Polym. Sci., 27, 381 (1958).

13. C. C. Price and J. Jomlefer, J. Amer. Chem. Soc., 72, 14 (1950).

14. L. J. Young, J. Polym. Sci., 27, 381 (1958).

15. C. G. Overberger, Chem. Ind. (London), 24 (1968).

16. H.E. Ramsden and N. J. Metuchen, U.S. Patent 2921964 (1960).

17. K. C. Frisch and R. B. Young, U.S. Patent 2671099 (1954).

18. C. Eaborn, J. Chem. Soc., 3077 (1950). 